\title{
Analysis, Design and Experimental Research of a Novel Bilateral Patient Transfer Robot
}

\author{
Lingfeng Sang $1, * \mathbb{C}$, Hongbo Wang ${ }^{2}$ and Yu Tian ${ }^{3}$ \\ 1 College of Mechanical and Electrical Engineering, Ningbo Polytechnic, Ningbo 315800, China \\ 2 Academy for Engineering \& Technology, Fudan University, Shanghai 200433, China; hongbo_w@ysu.edu.cn \\ 3 Parallel Robot and Mechatronic System Laboratory of Hebei Province, Yanshan University, \\ Qinhuangdao 066004, China; ysusirtian@163.com \\ * Correspondence: sanglingfeng@163.com
}

Citation: Sang, L.; Wang, H.; Tian, Y. Analysis, Design and Experimental Research of a Novel Bilateral Patient Transfer Robot. Machines 2022, 10, 33. https://doi.org/10.3390/machines 10010033

Academic Editor: Giuseppe Carbone

Received: 9 November 2021

Accepted: 3 December 2021

Published: 4 January 2022

Publisher's Note: MDPI stays neutral with regard to jurisdictional claims in published maps and institutional affiliations.

Copyright: (C) 2022 by the authors. Licensee MDPI, Basel, Switzerland. This article is an open access article distributed under the terms and conditions of the Creative Commons Attribution (CC BY) license (https:// creativecommons.org/licenses/by/ $4.0 /)$.

\begin{abstract}
Patient transfer has always been a difficult problem in the hospital. For medical staff, there are problems including high risk of infection, heavy physical labor and low efficiency of transfer; for patients, there are problems including poor comfort and secondary injury. In this paper, a novel bilateral patient transfer robot is investigated and designed. The following tasks are conducted: (1) Based on the process of patient transfer, a transfer model, which consists of two degrees of freedom, is proposed, and the working principle of bilateral patient transfer robot is obtained and analyzed in detail. (2) Force analysis of the patient transfer robot is conducted. The corresponding relationship between the patient comfort and the insertion angle is proposed, and the optimal sizes of mechanical structure are obtained. (3) Based on the theoretical analysis, the mechanical structure and the control system of the robot are designed, and the prototype is manufactured. (4) Experimental research is conducted. The results show that the prototype can complete the required motion performance with a carrying capacity up to $150 \mathrm{~kg}$ and patient comfort is excellent. The results of this paper prove that this kind of patient transfer robot has good performance, it can also reduce the burden on medical staff.
\end{abstract}

Keywords: bilateral patient transfer robot; mechanical design; force analysis; control system design; experimental research

\section{Introduction}

Patient transfer is the process of moving patients with limited mobility between wards, examination rooms, operating theatres and other parts of the hospital. It is one of the most common nursing tasks in the hospital [1]. At present, these tasks are still mainly carried out by means of manual transfer [2-4]. These transfer methods have some disadvantages, such as high work intensity, large number of personnel, high risk of infection and so on. The worldwide outbreak of COVID-19 in 2020 made the above problems more prominent. Meanwhile, with the continuous improvement of living standards and the deepening of the aging population, the numbers of obese patients, stroke patients and injured patients are increasing, and the numbers of patients who need auxiliary equipment to complete the transfer are also gradually increasing. Therefore, research surrounding a corresponding device, which can not only reduce the burden on medical staff, but also help patients to move safely, is highly important for medical staff and patients.

In order to meet their requirements, researchers and medical companies use relevant technologies to study how to achieve patient transfer under safe and effective circumstances and have developed some devices. These devices are mainly divided into three types: integrated patient transfer robot, split patient transfer robot and humanoid patient transfer robot.

(1) Integrated patient transfer robot:

The patient transfer part and the moving part of the robot are integrated. The mainly product is MOBILIZER 3, designed by Italy's SAVIR Company, and an SE patient transfer 
device, developed by Ningbo Kaifa Medical Technology Co., Ltd. in China [5-7]. The thickness of the patient transfer part of integrated patient transfer robot is about $15 \mathrm{~mm}$ by using the closed flat belt drive mechanism, and the control system is simple. In the process of transfer, the patient has no tilting feeling and has good comfort. These robots can only achieve unilateral patient transfer. Before transferring the patient, it is necessary to adjust the orientation of the robot according to the patient's direction in order to accurately achieve the transfer. In narrow areas, such as wards and operating rooms, it may be necessary to move the position of the sickbed. In addition, since the intelligent docking method is not adopted, it is necessary to adjust the height of the device several times during docking.

(2) Split patient transfer robot:

The split type means that the patient transfer part of the robot is separated from the moving part of the robot. The patient transfer part is used to realize the transfer of the patient between the devices, and the moving part of the robot is applied to complete the moving of the patient between different rooms. The products include PowerNurse, designed by Astir Technologies company in the United States [8,9]; C-Pam, developed by DAIHEN company in Japan [10,11]; a patient transfer robot prototype researched by the Institute of Medical Equipment, Academy of Military Medical Sciences of the Chinese People's Liberation Army [12]; a multi-module patient transfer robot prototype, analyzed by Yanshan University [13-15]. The patient transfer part of these robots is mostly designed with a multi-module structure, and each module adopts two layers of belt for transmission, the lower layer belt is used for the overall movement and the posture adjustment of the transfer part, and the upper layer belt is used for moving and for posture adjustment of the patient. The whole movement process depends on the coordination of the upper and lower layers of belt of multiple modules. The multi-module structure can complete posture adjustment of the patient and long-distance transfer of the patient. However, the patient transfer part is very thick, which makes the extrusion pressure on the patient very large in the transfer process, and the patient experiences a tilting feeling. In addition, when the patient transfer part leaves the moving part of the robot and enters the sickbed, the height above the sickbed decreases due to the gravity extrusion of the patient transfer part. There is no guarantee that the patient transfer part can be returned to the moving part smoothly.

(3) Humanoid patient transfer robot:

These robots use humanoid structures to imitate medical staff to achieve patient transfer. The corresponding products include RI-MAN [16,17], researched by the Japanese Institute of Science and Chemistry, RoNA nursing robot, designed by HStar Company in the United States [18] and "Dabai" robot, developed by Hebei University of Technology [19,20]. These robots, which are designed according to nursing and ergonomics, have a good structure, and some advanced sensor technologies are also be used, such as skin sensors applied in the RI-MAN robot and the Dabai robot. They can improve the security and the flexibility of the device. However, the transfer efficiency is low, and the humanmachine interaction is complex. Therefore, it is difficult to achieve industrialization of these products.

To sum up, the structure and function of these three types of patient transfer robots in the existing market do not fully meet the clinical and market requirements. In addition, the products are mostly developed from the perspective of practical application, and there are few theoretical studies. The relationship between patient comfort research evaluation method and mechanism optimization has not been established; therefore, the comprehensive evaluation of patient comfort cannot be realized.

Therefore, in this paper, based on the actual clinical requirements, working principle for the patient transfer robot is abstracted. On this basis, a novel bilateral patient transfer robot is proposed and designed. The integrated structure is applied in the patient transfer part and the moving part of the robot. The patient transfer part has the functions of backlifting and the bilateral movement to complete the patient transfer process, without moving 
the hospital device as soon as possible. These structures and functions can meet all the application scenarios in the hospital. In addition, a method of patient comfort evaluation is established by force analyzing the patient during the transfer process and analyzing the optimization of the structural parameters is achieved. The successful development of this robot can solve the problems of difficult application, promotion and industrialization of existing devices.

This paper is organized as follows: working principle and force analysis for the patient transfer robot is analyzed in detail in Section 2. Innovative design of the mechanical structure is introduced in Section 3. Design of control system is conducted in Section 4. Experiments for patient comfort and the carrying capacity are researched in Section 5 . The conclusion and proposals for future work are given in Section 6.

\section{Analysis of the Working Principle for the Patient Transfer Robot}

\subsection{Analysis of the Working Principle for the Bilateral Movement in Patient Transfer}

In order to analysis the transfer process, the severe patient was selected as the research object and a corresponding clinical transfer process was analyzed; the transfer model, consisting of two degrees of freedom (the forward motion and the rotation motion), is obtained, as shown in Figure 1.

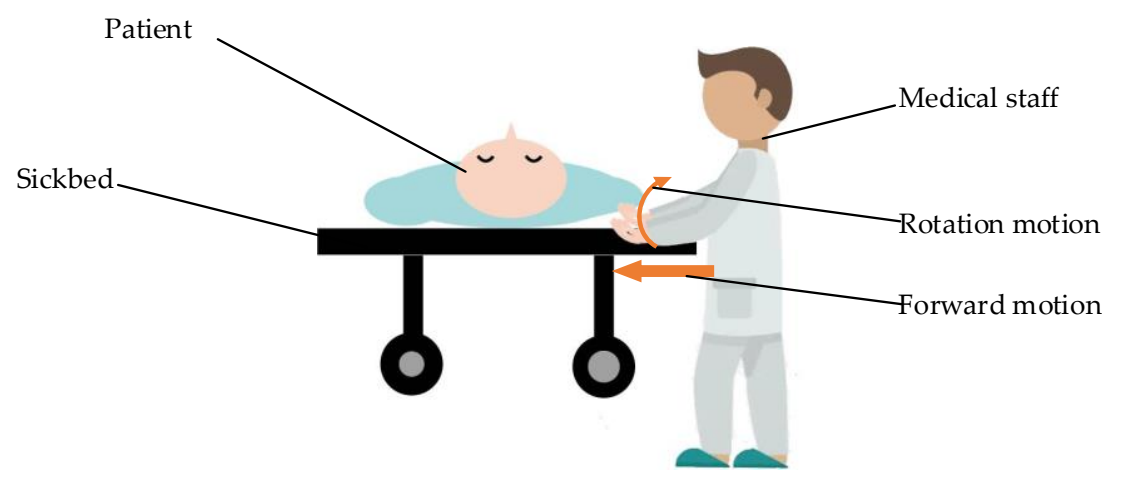

Figure 1. Clinical transfer process of patients.

In order to simulate the operating process of the medical staff, the moving panel is used to replace the hand of the medical staff and the transfer belt is used to replace the lifting process of the hand under the patient. Additionally, the roller is used to replace the contact process between the hand and the sickbed surface, as shown in Figure 2. Therefore, a simplified mechanism from the clinical transfer can be obtained.

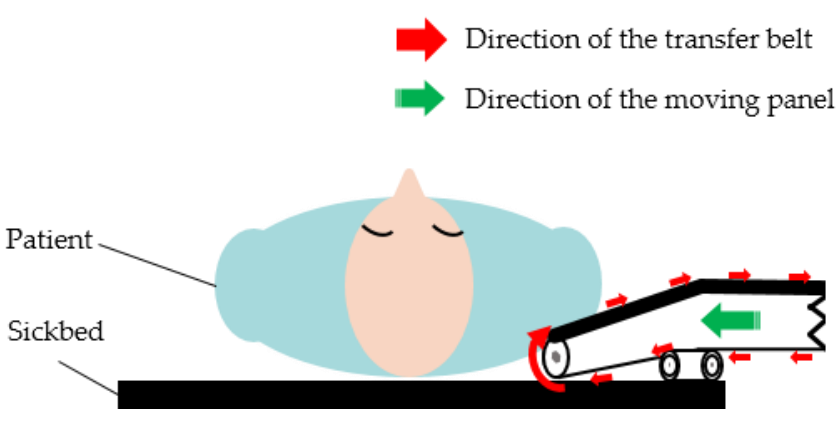

Figure 2. Clinical transformation of patient transfer process.

The patient transfer could be realized through the coordination of the moving panel and the transfer belt. When the moving panel and the transfer belt move at the same time, the patient can be transferred to the moving panel or removed from the moving panel; when the moving panel moves and the transfer belt does not move, the patient can be moved between the sickbed and the patient transfer robot. In the hospital, some sickbeds 
are arranged against the wall or the window, and bedside tables are placed between the sickbeds. If the patient is transferred and moved by the medical staff by the sides of the sickbed, there is no need to consider the direction; however, if the patient transfer robot is used, due to the limitation of ward space, four states need to be analyzed, as follows: I. transferring, moving and placing the patient down, from the right of the sickbed; II. transferring, moving and placing the patient down, from the left of the sickbed; III. transferring and moving from the right of the sickbed, placing the patient down from the left of the sickbed; IV. transferring and moving from the left of the sickbed, placing the patient down from the right of the sickbed. Therefore, the working principle of the patient transfer robot can be obtained, as shown in Figure 3.

According to clinical requirements, some patients may need to be transferred with back-lifting. Hence, based on the modular design idea, the moving panel is divided into the horizontal plate module and the backplane module. The backplane module not only carries out the back movement, but also translates with the horizontal plate. The mechanism motion diagram is shown in Figure 4.

State I:

$\longrightarrow$ Direction of the transferbelt

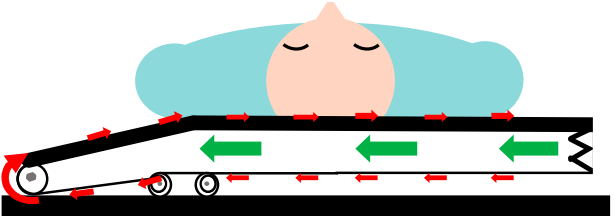

(a)

State II:

State III:

State IV: (c)

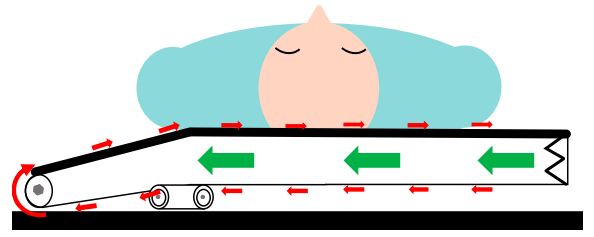

(e)

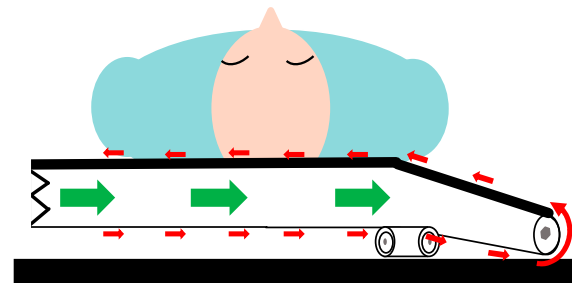

$(\mathrm{g})$

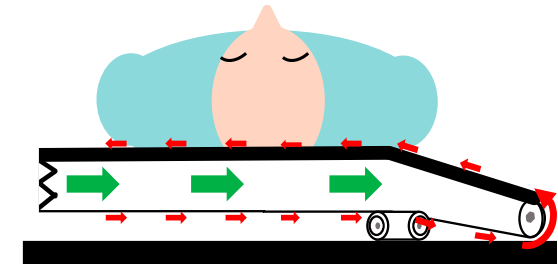

Direction of the moving panel

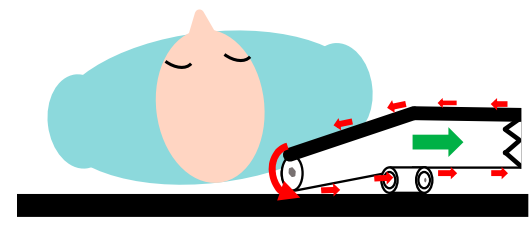

(b)

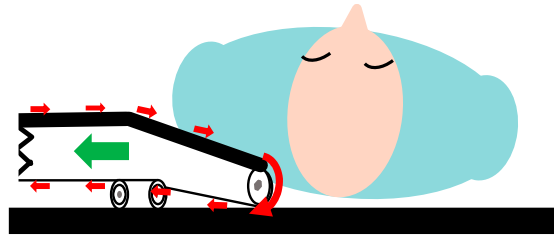

(d)

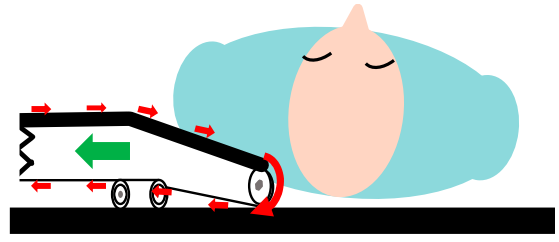

(f)

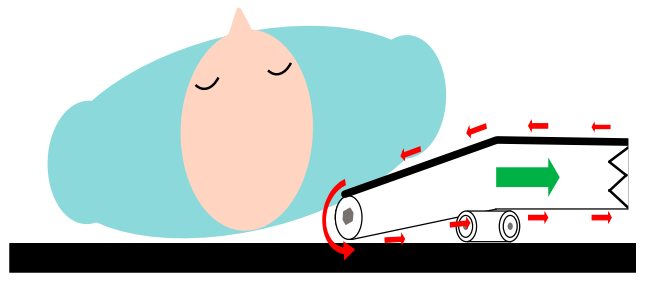

(h)

Figure 3. Working principles diagram of patient transfer robot. (a) Lifting and transferring patient from the left side of the sickbed; (b) placing the patient down from the left of the sickbed; (c) lifting and transferring patient from the right side of the sickbed; (d) placing the patient down from the right side of the sickbed; (e) Lifting and transferring patient from the left side of the sickbed; (f) placing the patient down from the right side of the sickbed; (g) lifting and transferring the patient from the right side of the sickbed; (h) placing the patient down from the left of the sickbed. 


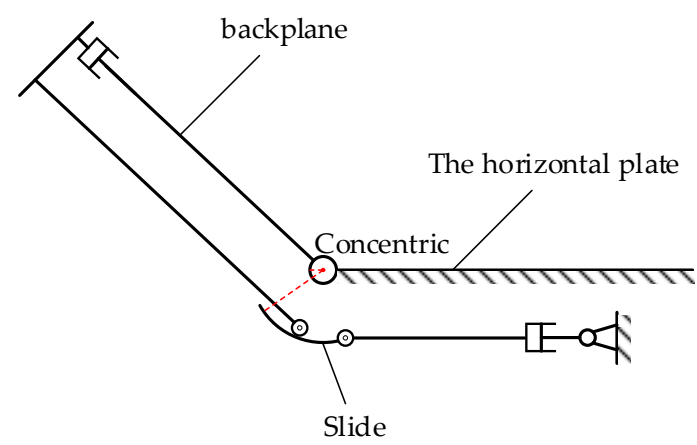

Figure 4. Mechanism motion diagram of the moving panel.

Based on Figure 4, the degree of freedom of the mechanism can be computed [21] by the following:

$$
f_{\text {dof }}=3 n-2 p_{L}-p_{H}=3 \times 4-2 \times 5-1=1
$$

where $f_{\text {dof }}$ is the degree of freedom, $n$ is the number of active components, $p_{L}$ is the number of low pair and $p_{H}$ is the number of high pair.

The movement of the moving panel could be realized by a motor. Due to the modular design of the backplane and the horizontal plate, the transfer belts on these two parts need to be controlled, respectively, and each transfer belt is fixed with an open loop, i.e., the two ends of the transfer belt are fixed to roller 1 and roller 2, respectively. This can realize the movement of the transfer belt on the surface of the moving plate and complete the patient transfer when one of the rollers tightens the belt and the other releases. Each transfer belt is driven by two motors, so a total of four motors are needed to complete the drive of the transfer belt. The schematic diagram of the mechanism driven by the motor is shown in Figure 5.

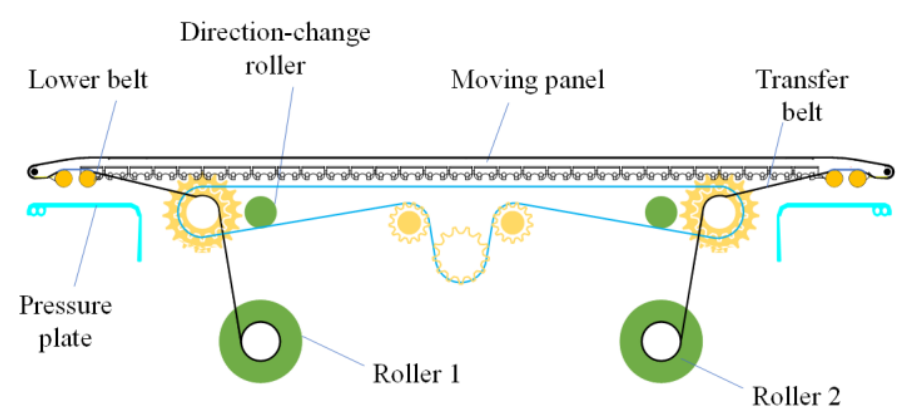

Figure 5. Transmission mechanism diagram of the moving panel and the transfer belt.

\subsection{Force Analysis and Optimation of the Patient Transfer Robot}

In the process of designing the mechanism, angle $\theta$, which is at the insertion end of the moving panel, is very important to the performance of the robot. It has a direct impact on the comfort of the patient. If the angle $\theta$ is too large during transferring, the patient experiences a significant feeling of tilting. Therefore, it is necessary to establish the mathematical relationship between the comfort of patient and the angle $\theta$.

Through the analysis of the patient's movement process in the previous section, it can be found that the process for lifting and transferring patient has the greatest influence on the comfort of the patient. Therefore, the comfort of the patient in this process is studied, and the key structural parameters of the robot are determined.

The patient is taken as the research object for force analysis, as shown in Figure 6. 


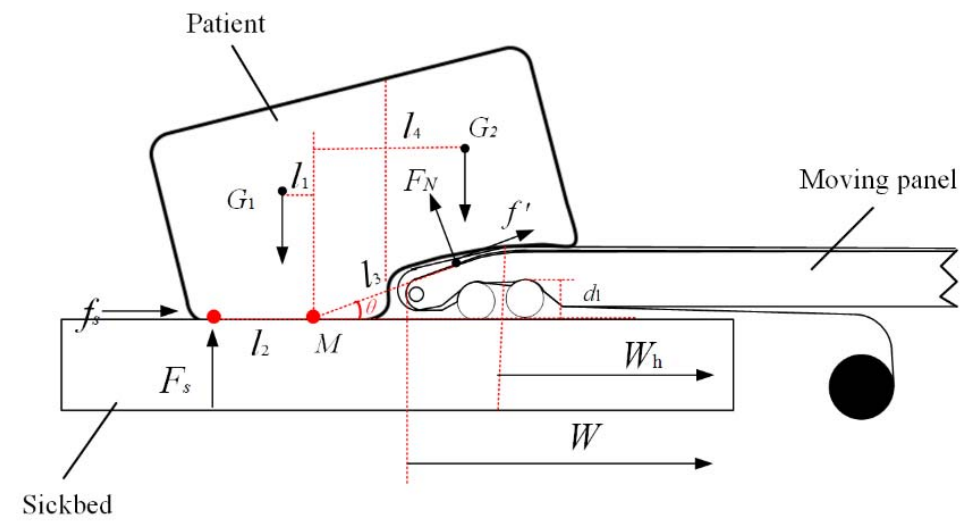

Figure 6. Force analysis model at insertion end of the patient transfer robot.

Considering safety of the patient, the robot is operated at a low speed $(<30 \mathrm{~mm} / \mathrm{s})$ when transferring, so only statics equations are established. The overall weight $G$ of the patient is split into $G_{1}$ and $G_{2} . G_{1}$ is the weight of the patient on the bed, and $G_{2}$ is the weight of the patient on the inclined surface of the moving panel. The point $M$ is the intersection of extension line of the inclined surface and of the sickbed surface. Based on Figure 6, the statics equations at point $M$ could be obtained as follows:

$$
\left\{\begin{array}{l}
f_{s}+f^{\prime} \cdot \cos \theta=F_{N} \cdot \sin \theta \\
G_{1}+G_{2}=F_{s}+F_{N} \cdot \cos \theta+f^{\prime} \cdot \sin \theta \\
G_{1} \cdot l_{1}-F_{s} \cdot l_{2}-G_{2} \cdot l_{4}+F_{N} \cdot l_{3}=0
\end{array}\right.
$$

where $f_{s}$ is the static friction between the sickbed and the patient; $f^{\prime}$ is the static friction between the inclined surface and the patient; $\theta$ is the angle between the direction of the inclined surface and the horizontal direction; $F_{N}$ is the force of the inclined surface against the patient; $F_{S}$ is the force of the sickbed against the weight $G_{1}$ of the patient; $l_{1}$ is the distance between the applied point of the weight $G_{1}$ and the point $M ; l_{2}$ is the distance between the applied point of the force $F_{S}$ and the point $M ; l_{3}$ is the distance between center of the inclined surface and the point $M ; l_{4}$ is the distance between the applied point of the weight $G_{2}$ and the point $M$.

In order to assess the feeling of the patient during transferring, an in-depth analysis of Equation (2) needed to be performed. Observing the force analysis in $x$-axis direction, it is found that all the static friction forces are on the left of the equation. If the resultant force of these static friction is smaller, the patient will feel more comfortable; and the conclusion has also been verified by real experiments. Therefore, the minimum value of the resultant force of the static friction force is taken as the evaluation index $H$ of patient comfort, and it is described by the following expression:

$$
H=\min \left(f_{s}+f^{\prime} \cdot \cos \theta\right)
$$

Combining Equations (2) and (3), the following equation is obtained:

$$
H=\min \left(\frac{-G_{1} \cdot l_{1}+F_{S} \cdot l_{2}+G_{2} \cdot l_{4}}{l_{3}} \sin \theta\right)
$$

According to Equation (4), the index $H$ is proportional to the insertion angle $\theta$. Hence, the optimization of the index $H$ is equivalent to the optimization of the insertion angle $\theta$, within certain constraint conditions. Based on ergonomics and national standards of body size [22-24], the constraints are set as follows:

$$
\left\{\begin{array}{l}
438 \mathrm{~mm} \leq W_{h} \leq 700 \mathrm{~mm} \\
22 \mathrm{~mm}<h<25 \mathrm{~mm} \\
W_{h}<W<700 \mathrm{~mm}
\end{array}\right.
$$


where $W_{h}$ is the horizontal width of the moving panel, $h$ is the thickness of the moving panel and $W$ is the overall width of the moving panel.

Combining Equations (4) and (5), the following equation could be described:

$$
\left\{\begin{array}{l}
\theta=\arctan \left(\frac{2\left(h-d_{l}\right)}{W-W_{h}}\right) \\
l_{3}=\frac{h+d_{l}}{2 \cdot \cos \left(90^{\circ}-\theta\right)}
\end{array}\right.
$$

where $d_{l}$ is the height size of the lower belt and $d_{l}=13 \mathrm{~mm}$.

The patient's body weight is assumed to be evenly distributed. At certain time points during patient transfer, the relative position of the patient and the transfer robot is determined. The comforts of the patient in this state are simulated by MATLAB and the results are shown in Figure 7.

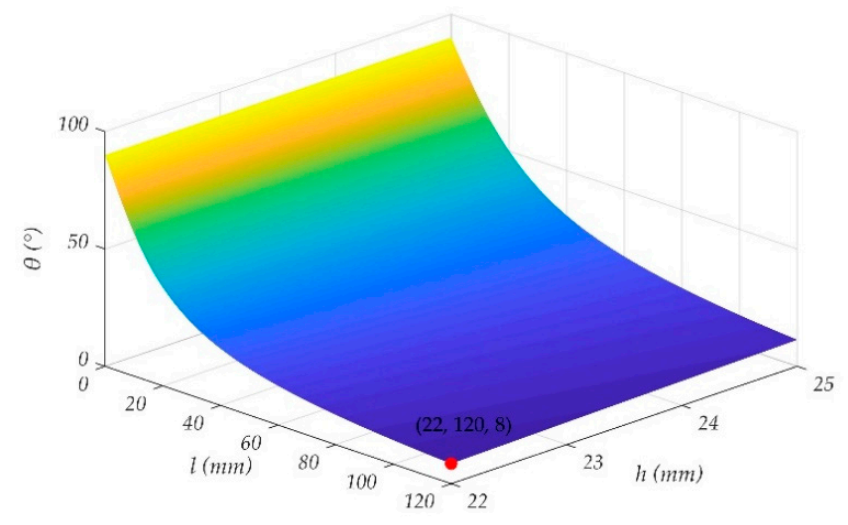

(a)

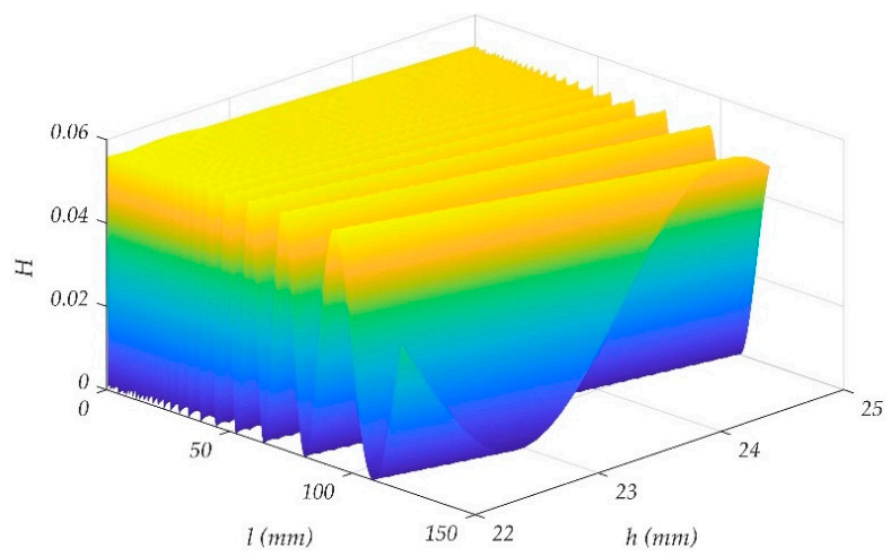

(b)

Figure 7. Simulation of key structural parameters of patient transfer robot. (a) The change surface of the insertion angle $\theta ;(\mathbf{b})$ the change in the surface of the index $H$.

From the simulation results, the key structural parameters are obtained, as follows: the thickness size $h$ of the moving panel is $22 \mathrm{~mm}$, the horizontal projection length size for the inclined surface of the moving panel is $120 \mathrm{~mm}$, and the insertion angle is $8^{\circ}$.

\subsection{Driving Force Analysis of the Moving Panel}

Driving force analysis is the key to selection of the motor. In the whole moving panel part, the movement of the moving panel and the movement of the transfer belt need to be driven by the motor; therefore, the driving force of these two cases were analyzed, respectively.

\subsubsection{Analysis Force of the Transfer Belt}

Taking the transfer belt as the research object, the force analysis was conducted, as shown in Figure 8. 


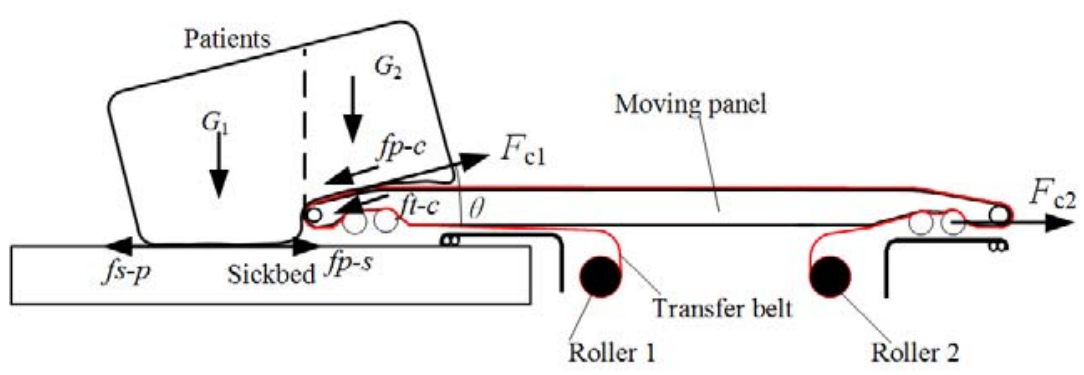

Figure 8. Driving force analysis of the transfer belt.

Assuming that the roller 1 releases the transfer belt and roller 2 tightens the transfer belt, only the force on roller 2 needs to be analyzed, and the following expression can be obtained:

$$
\left\{\begin{array}{l}
F_{c 1}=f_{t-c}+\left(f_{p-c}+f_{s-p} \cdot \cos \theta\right) \\
f_{t-c}=\mu_{1} G_{2} \cdot \cos \theta \\
F_{c 2}=\mu_{2} F_{c 1} \\
F_{c}=F_{c 1}+F_{c 2}
\end{array}\right.
$$

where $f_{t-c}$ is the sliding friction force between the moving panel and the transfer belt; $f_{p-c}$ is the static friction force between the patient and the transfer belt; $f_{s-p}$ is the static friction force between the sickbed and the patient; $F_{c 1}$ is the tensile force of the transfer belt; $\mu_{1}$ is the sliding friction coefficient between the moving panel and the transfer belt; $\mu_{2}$ is the rolling friction coefficient between the transfer belt and the plastic roller; $F_{c 2}$ is the rolling friction force of the transfer belt on the roller; $F_{c}$ is the resultant force of the transfer belt. The force in each position of the tensile part on the transfer belt is the same. when the transfer belt passes over the plastic rollers of the lower belt, the transfer belt applies force on the plastic roller, which causes the rolling friction force. So $F_{\mathrm{c} 2}$ could be computed by the tensile $F_{\mathrm{c} 1}$ and the rolling friction coefficient $\mu_{2}$, and the tensile of the roller 2 could be obtained by $F_{\mathrm{c} 1}$ and $F_{\mathrm{c} 2}$.

When the linear velocity $v_{m}$ of the moving panel is equal to the linear velocity $v_{b}$ of the transfer belt, the values of the two static friction forces $f_{p-c}$ and $f_{s-p}$ are close to zero, so their values could be ignored. With the coordinated movement of the moving panel and the transfer belt, the patient gradually moved from the inclined plane to the horizontal plane. When the whole body of the patient is moved to the horizontal plane of the moving panel, the value of $F_{c 1}$ is the maximum, and the expression is described as follows:

$$
F_{c 1 \max }=\max \left\{f_{t-c}\right\}=\mu_{1} G
$$

As for the materials, the transfer belt is made of woven material, the moving panel is made of aluminum, and the roller is made of plastic. Based on knowledge of materials science, the values of friction coefficient could be described as follows:

$$
\mu_{1}=0.5, \mu_{2}=0.1
$$

Combining equations from (7) to (9), the maximum for the resultant force of the transfer belt can be obtained as

$$
F_{c \max }=K_{1} \cdot\left(F_{c 1 \max }+\mu_{2} \cdot F_{c 1 \max }\right)=990 \mathrm{~N}
$$

where $K_{1}$ is the safety factor and $K_{1}=1.2, G=1500 \mathrm{~N}$.

Therefore, the carrying capacity is not less than $990 \mathrm{~N}$ when the motor of the transfer belt is selected.

\subsubsection{Analysis Force of the Moving Panel}

Taking the moving panel as the research object, the force analysis was conducted, as shown in Figure 9. 


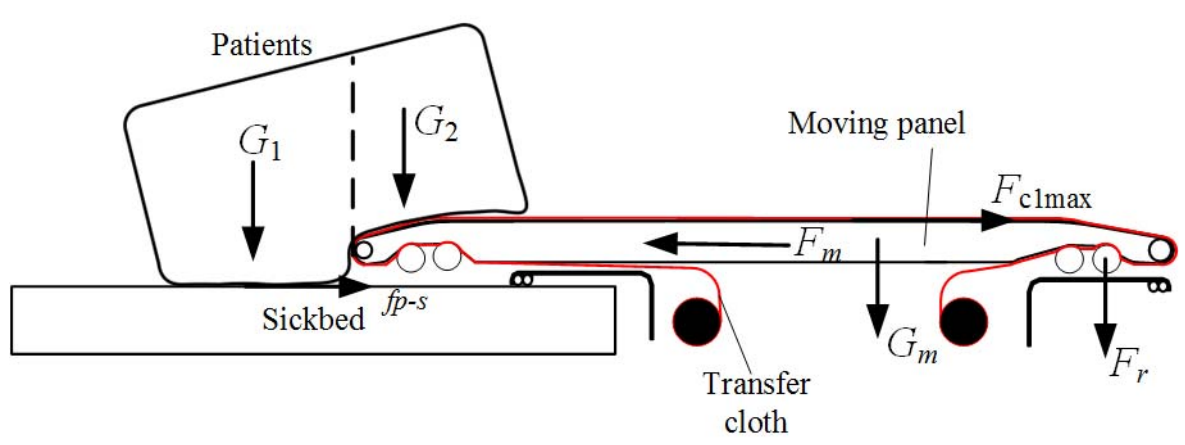

Figure 9. Driving force analysis of the moving panel.

According to the force analysis, the following equations could be obtained:

$$
\left\{\begin{array}{l}
F_{m}=\mu_{3} F_{N}^{m}+F_{c 1 \max }+f_{p-s} \\
F_{N}^{m}=F_{r}+G_{m}+G \\
\left|F_{r}\right|=\left|F_{c 1 \text { max }}\right|
\end{array}\right.
$$

where $F_{m}$ is the driving force of the moving panel; $F_{N}^{m}$ is the positive pressure of the moving panel on the slide rail; $\mu_{3}$ is the sliding friction coefficient between the moving panel and sliding rail and $\mu_{3}=0.1 ; f_{p-s}$ is the static friction coefficient between the sickbed and the patient; $F_{r}$ is the positive pressure of the transfer belt on the slide rail; $G_{m}$ is the weight of the moving panel.

Assuming that the linear velocity $v_{m}$ of the moving panel is equal to the linear velocity $v_{b}$ of the transfer belt, it is obtained that the static friction force $f_{p-s}$ is zero. Therefore, the required maximum force to the moving panel can be obtained as follows:

$$
F_{m}=K_{2}\left(\mu_{3} \max \left\{F_{N}^{m}\right\}+F_{c 1 \max }\right) \approx 1254 \mathrm{~N}
$$

where $K_{2}$ is safety factor and $K_{2}=1.1, G_{\mathrm{m}}=200 \mathrm{~N}$.

Therefore, the carrying capacity is not less than $1254 \mathrm{~N}$ when the motor of the moving panel is selected.

\section{Mechanical Structure Design of the Patient Transfer Robot}

The structural design of the patient transfer robot mainly includes the patient transfer part and the moving part. The patient transfer part is mainly used to realize the patient transfer during the robot and the different device, and the moving part is mainly applied to complete power-assisted moving and lifting of the robot.

\subsection{The Structural Design of the Patient Transfer Part}

The structural design of the patient transfer part mainly includes the transverse driving part, the back-lifting part and the moving panel part.

\subsubsection{The Structural Design of the Transverse Driving Part}

The transverse driving part runs very slowly and there is a long transmission distance, the sprocket chain structure is adopted in this section. The closed chain is formed by sprocket 3 and sprocket 5 to guarantee that the moving panel will work when it is separated from one side of the sprocket and returned again in the process of bilateral movement. Through the closed chain connection of sprocket 2 and sprocket 4 , the driving force of reduction motor can be transferred to the transverse drive roller. Depending on the clutch structure, the driving end and the drive chain end can be separated, and the moving panel can be assembled and adjusted quickly. In order to ensure that the sprocket structure is not exposed in the process of the moving movement, the sprocket is shielded by matching the cable box and the sprocket cover. The overall structure design of the transverse driving part is shown in Figure 10. 


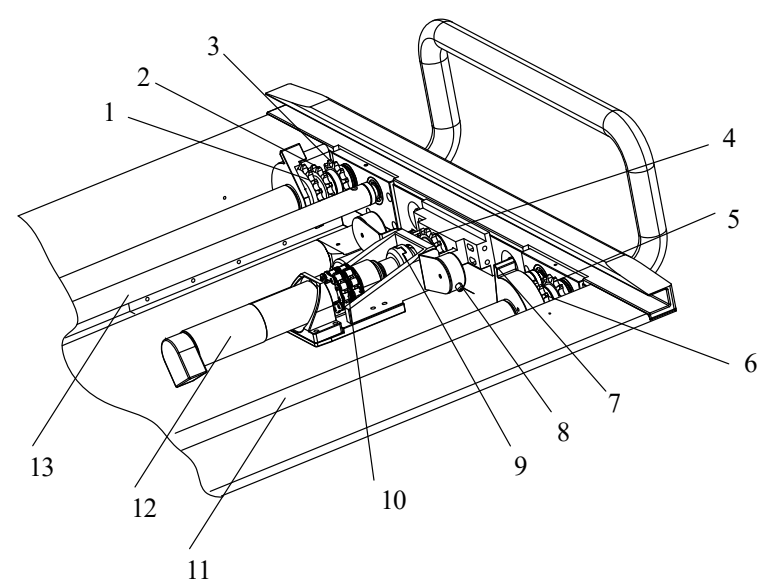

Figure 10. The structural design of the transverse driving part; 1 -sprocket $1 ; 2$-sprocket $2 ; 3$ sprocket 3; 4-sprocket 4; 5 -sprocket 5; 6-sprocket 6; 7-the sprocket cover; 8-the cable box; 9-the clutch structure; 10 - the coupling with the sprocket chain structure; 11 - the transverse drive roller; 12-the brushless DC reduction motor; 13-the direction-change roller.

\subsubsection{The Structural Design of the Back-Lifting Part}

According to Figure 4, the structural design of the back-lifting part is shown in Figure 11. The whole back-lifting structure is realized by the back-lifting push rod, and the movement track is guaranteed by the back-lifting wheel frame and back-lifting chute. In order to ensure the smooth operation of the mechanism, double chute and double wheel frame structures are used. The angle range of the back-lifting part is designed from $0^{\circ}$ to $75^{\circ}$, based on ergonomics.

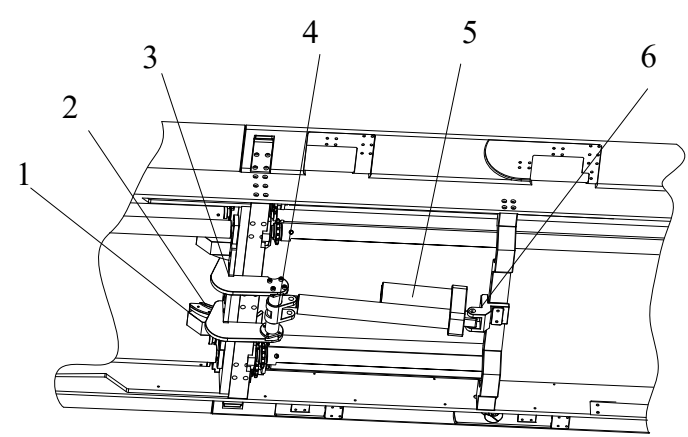

Figure 11. The structural design of the back-lifting part; 1 -back-lifting chute; 2 -the back-lifting wheel frame; 3-the ear bracket of the push rod; 4-the head bracket of the push rod; 5-the push rod; 6 - the end bracket of the push rod.

\subsubsection{The Structural Design of the Moving Panel}

The structural design of the moving panel is shown in Figure 12. The horizontal plate and the back-lifting plate are connected by five hinges. In the process of movement, the moving panel is positioned by the positioning slide in the middle, the flanged chain on the left and the flanged chain on the right. The slide block on the side of the back-lifting plate can slide freely in the guide rail. The two lower belts of the horizontal plate and the back-lifting plate are designed to prevent the sheets from being sucked into the device and to ensure that the moving panel does not crush the bed surface in the process of movement. In addition, the two lower belts could be quickly removed, cleaned and disinfected to prevent cross-infection. 


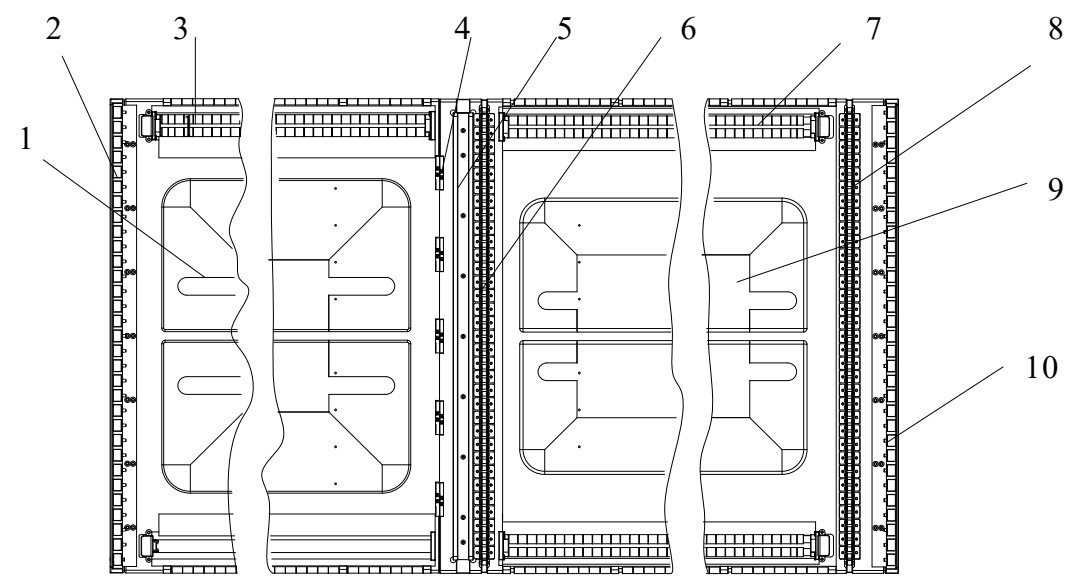

Figure 12. Fracture diagram of the structural design of the moving panel; 1 - the back-lifting plate; 2-the slide rail on the left; 3 -the lower belt of the back-lifting plate; 4-the hinge; 5 -the positioning slide; 6-the flanged chain on the left; 7-the lower belt of the horizontal plate; 8-the flanged chain on the right; 9 -the horizontal plate; 10 - the slide rail on the right.

\subsection{The Structural Design of the Moving Part}

The structural design of the moving part is mainly composed of the power-assisted moving part and the lifting part.

\subsubsection{The Structural Design of the Lifting Part}

The structural design is shown in Figure 13. The four castors are controlled to work in three straight, universal and locked states through the brake; they are used to realize the motion of the moving part. The two lifting columns are connected with the patient transfer part by the fixed plate, the connecting shaft and the self-aligning ball bearings.

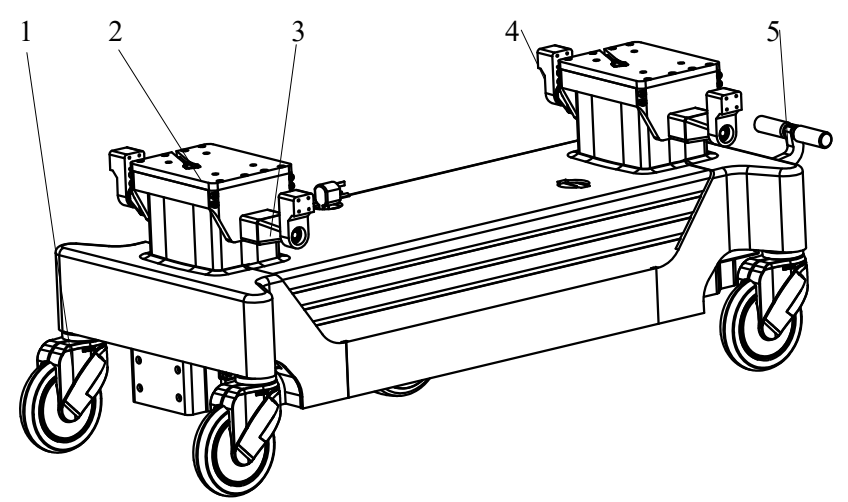

Figure 13. The structural design of the lifting part; 1 -the castor; 2 -the fixed plate of the lifting columns; 3-the connecting shaft; 4-the bearing support; 5-the brake.

\subsubsection{The Structural Design of the Power-Assisted Moving Part}

The structure of the power-assisted wheel is designed to make the robot move more easily, as shown in Figure 14. When the robot enters the elevator and moves up some small steps, the height difference will affect the work of the power-assisted wheel. In order to ensure that the robot can still work normally in this state, the swing mechanism with the gas spring is applied. The lifting motion for the structural of the power-assisted wheel is implemented by the dovetail mechanism. 


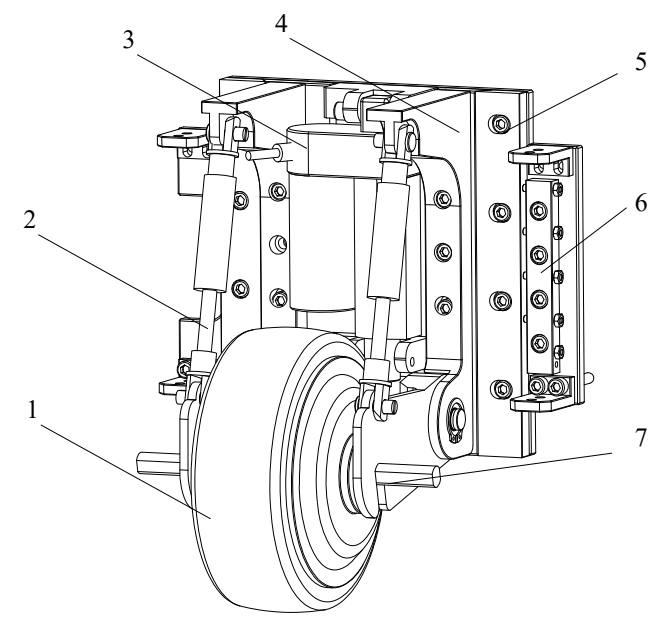

Figure 14. The structural design of the power-assisted moving part; 1 -the power-assisted wheel; 2-the gas spring; 3-the push rod; 4-the support of the gas spring; 5-the pressure plate of the dovetail groove; 6-the adjust block of the dovetail groove; 7-the support of the power-assisted wheel.

\section{Control System Design of the Patient Transfer Robot}

The realization of the motion functions for patient transfer robot is the reasonable design of control system. Therefore, the overall configuration of the control system is introduced, and the core components of the control system were designed, as shown in Figure 15.

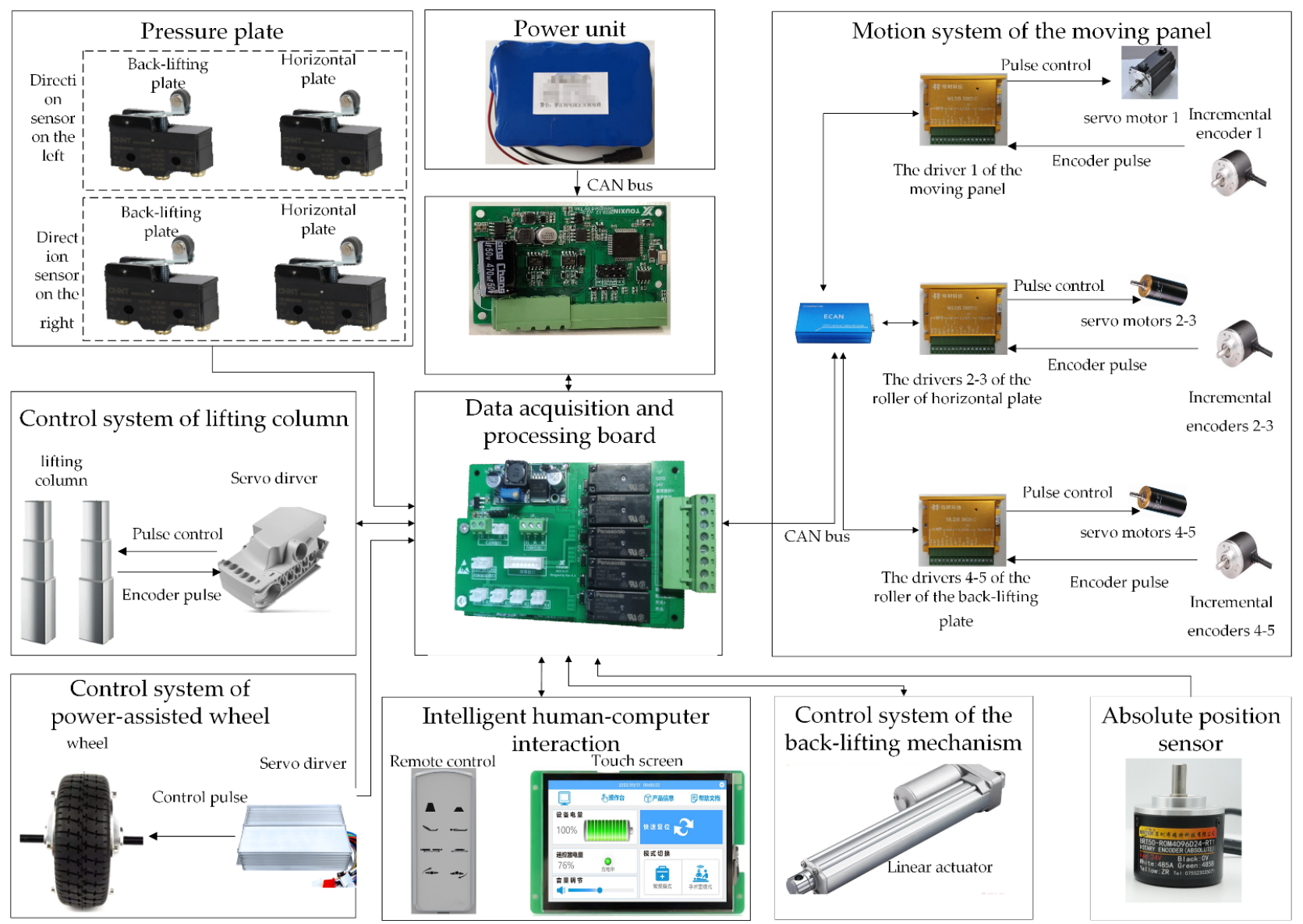

Figure 15. The control system of the patient transfer robot. 
The actuators of the control system are composed of the five brushless direct current motors, two lifting columns, one power-assisted wheel and one electric push rod in the back, and each of them has an independent driver. Patient transfer robot is powered by a high-capacity lithium battery pack. Besides, it has four direction sensors and one absolute position sensor. The direction sensor is installed on the pressure plate, and it is used to determine the transfer direction of the patient. The absolute position sensor is used to determine the position of the moving panel. In order for the medical staff to better control the robot, two methods of human-machine interaction are applied: remote control and touch screen.

In the whole control system, the coordinated motion of the five brushless direct current motors in the patient transfer part is relatively complex. Figure 16 shows the whole flow chart when the patient is transferred on the left of the sickbed. According to the process, motion control at different stages can be calculated.

The linear velocity $v_{m}$ of the moving panel could be computed by the following equation:

$$
v_{\mathrm{m}}=\frac{p_{p} \times z_{p}}{60 \times n_{d}} \times n_{p}
$$

where $p_{p}$ is the pitch of the sprocket $1, z_{p}$ is the number of teeth of the sprocket $1, n_{p}$ is the speed of the motor and $n_{d}$ is the reduction ratio of the motor.

The linear velocity $v_{b}$ of the transfer belt is realized by the coordinated movement of the two rollers. The linear velocity $n_{b r}$ of the roller can be calculated according to the following equation:

$$
v_{b r}=\frac{2 \pi(r+b)}{60 \times n_{r}} \times n_{b}
$$

where $r$ is diameter of the roller, $b$ is the unilateral thickness of the belt on the roller, $n_{b}$ is the speed of the roller and $n_{r}$ is the reduction ratio of the roller motor.

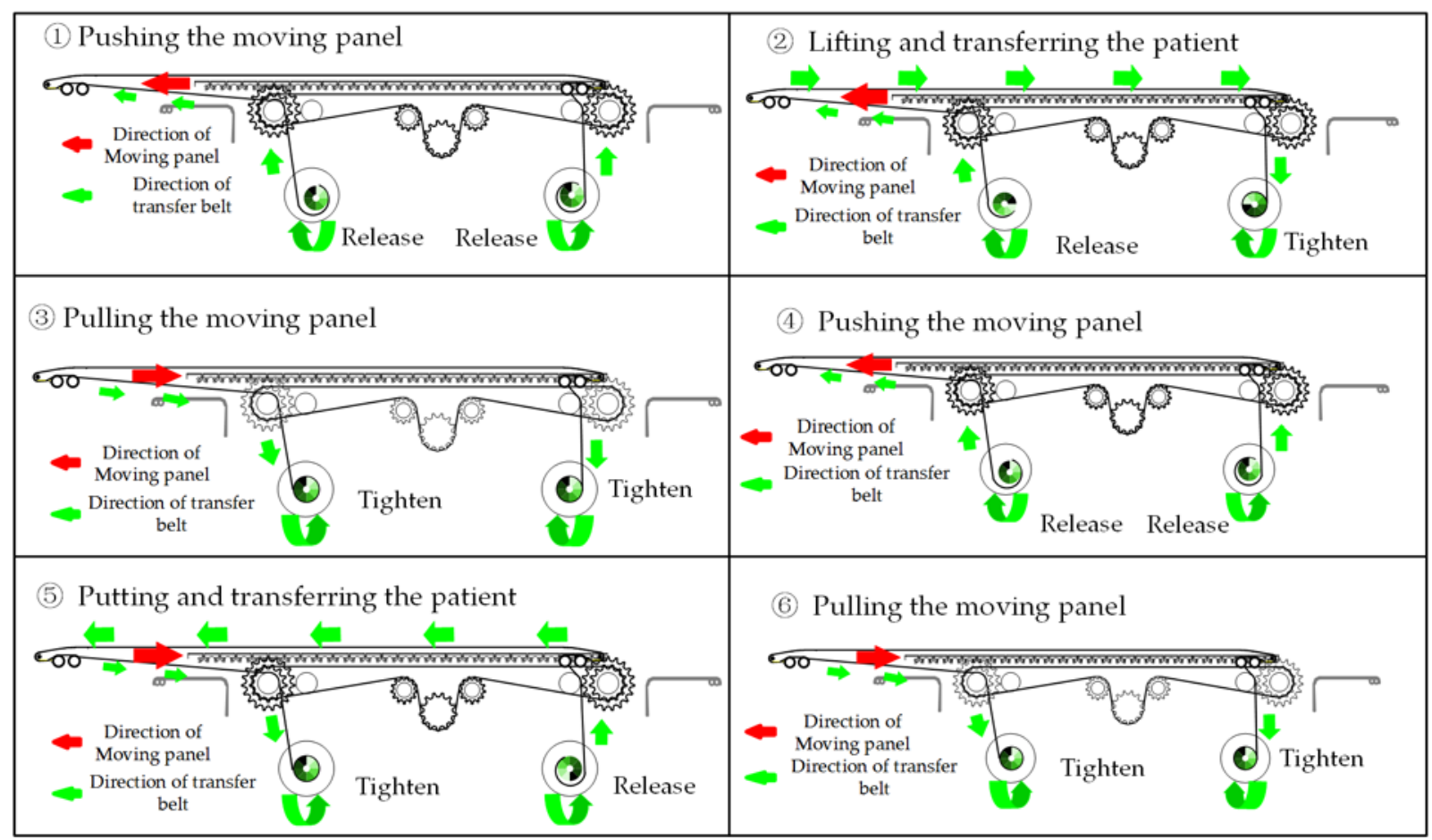

Figure 16. The whole flow chart of patient transfer on the left.

When patient is lifted and put between the robot and the sickbed, the following equation could be obtained:

$$
v_{m}=-v_{b}
$$


When the patient is stationary relative to the moving panel, the following equations could be obtained:

$$
\left\{\begin{array}{l}
v_{b}=0 \\
v_{m}=c
\end{array}\right.
$$

where $c$ is constant.

\section{Preliminary Tests of the Patient Transfer Robot}

\subsection{Prototype of the Patient Transfer Robot}

According to the above structural design and control system analysis, a prototype of the robot is developed, as shown in Figure 17. The wireless remote control is placed in the box of touch screen and is charged by the battery of the robot. Meanwhile, the electric quantity of the remote control can also be displayed on the touch screen and the whole robot only needs one charging wire to complete charging. Since each transfer belt is fixed with an open loop, it needs to reset the robot when each patient transfer process is completed. In order to prevent wrong operation from the medical staff, the reset button is set on the touch screen.

In order to verify motion function of the robot, we simulated its working environment in hospital experiments requiring transfer function. Firstly, a volunteer was moved from the sickbed to the moving panel of the robot. Then, in the state of the back-lifting of the volunteer, the robot automatically docked with the stretcher. Finally, the volunteer was transferred from the robot to the stretcher. The whole test process is shown in Figure 18. Observing the motion process, it was found that the robot runs stably and reliably, which verifies the correctness of the robot's motion function.

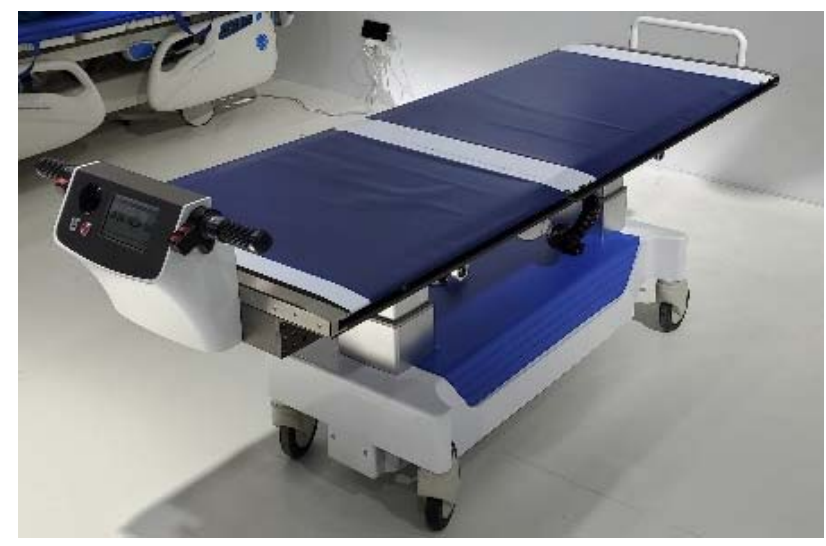

(a)

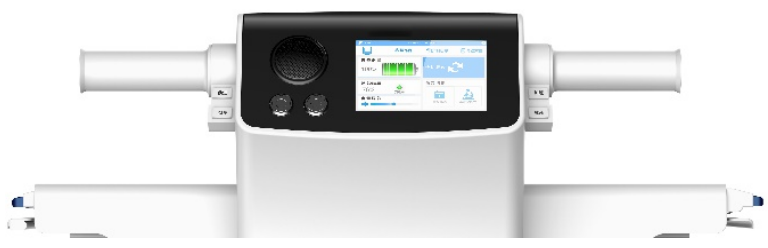

(b)

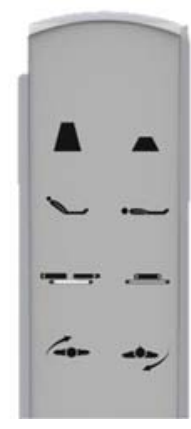

(c)

Figure 17. Prototype of the patient transfer robot. (a) Body of the patient transfer robot; (b) touchscreen control; (c) remote control. 


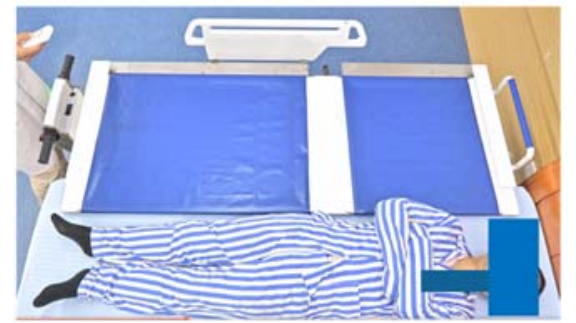

(a)

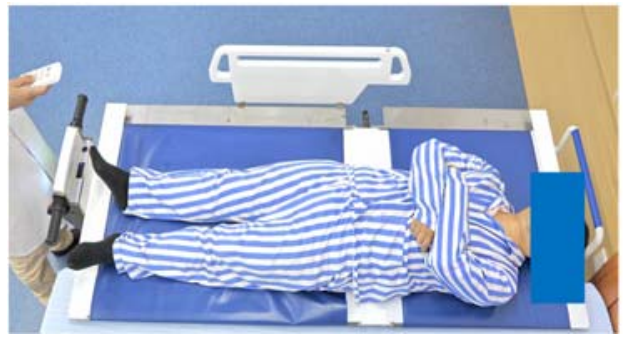

(c)

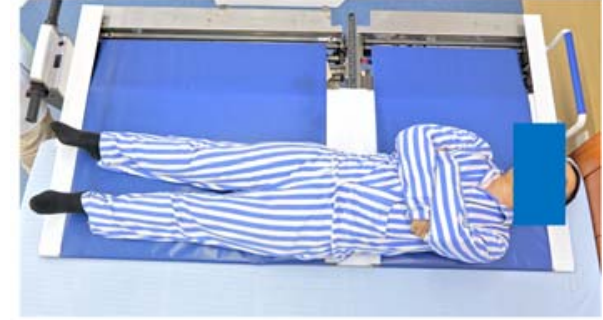

(b)

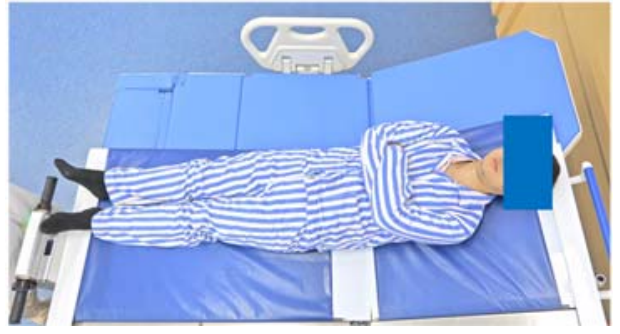

(d)

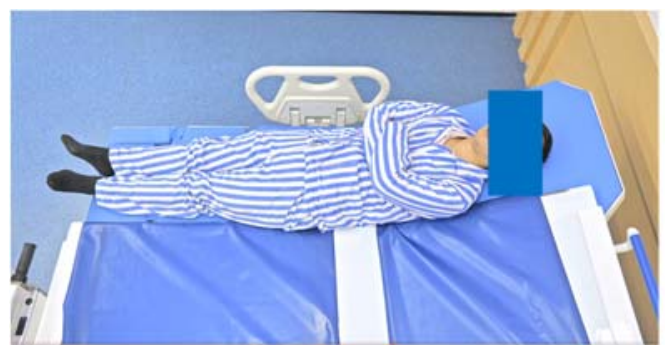

(e)

Figure 18. Experimental study on the motion function of the patient-transferring robot. (a) Pushing the moving panel; (b) lifting and transferring patient from the sickbed to the robot; (c) pulling the moving panel; (d) lifting the back of the patient and pushing the moving panel; (e) transferring and placing the patient from the robot to the stretcher.

\subsection{Test for the Effect of Insertion Angle on Patient Comfort}

In order to confirm the influence of the insertion angle on patient comfort, single-arm objective performance criteria were used. Based on the sample size estimation method for single-arm criteria, 60 volunteers are selected [25].

The height and weight of the volunteer had a great influence on the experimental results. In order to ensure the accuracy of the evaluation results, the height and weight of the volunteers should basically satisfy the normal distribution. Since the height and weight of female patients were lower than that of men of the same level, it is easier to meet the requirements of patient comfort. Therefore, only 10 female volunteers are selected during the selection of volunteers. The basic information of the volunteers are shown in Figure 19.

Before the experiments, all the volunteers completed a basic personal information form (including weight, height, gender, etc.) and signed a safety pledge. They were informed of safety measures, including having their hair up, being appropriately dressed and asking for help in time. The caregivers were informed of the safety operation procedures, including maintaining a slow pace, observing the device at all times and stopping the device at the appropriate time. 


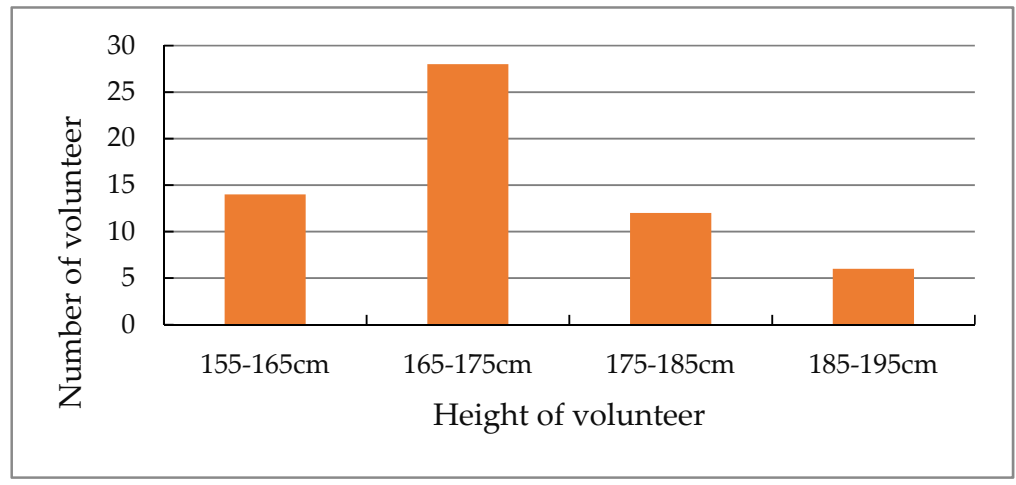

(a)

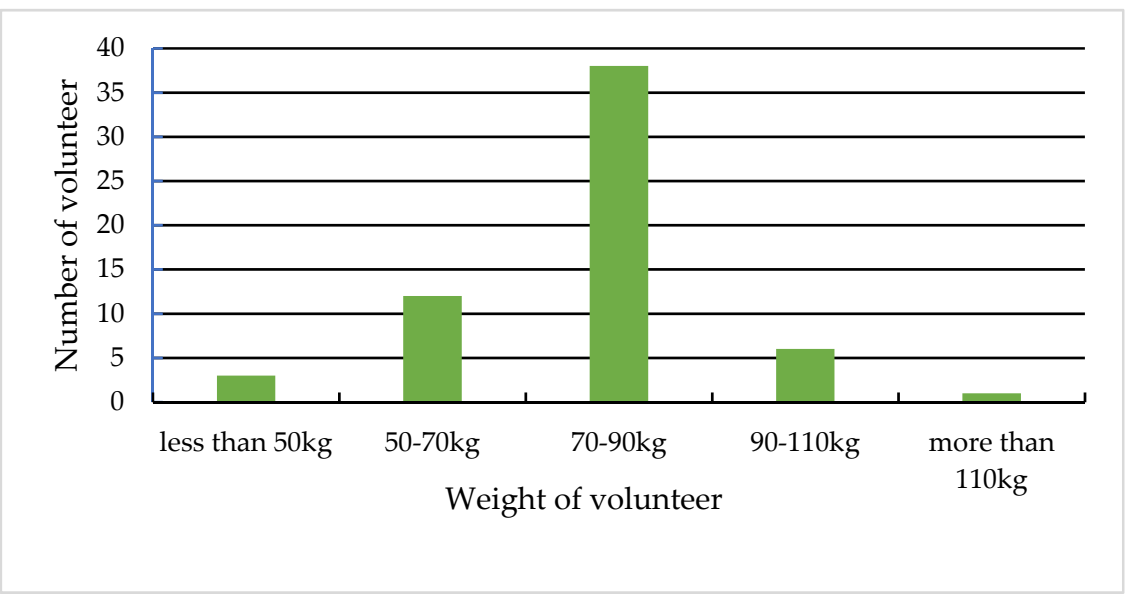

(b)

Figure 19. The basic information of the volunteer. (a) The distribution of the volunteers under the height factor; (b) the distribution of the volunteers under the weight factor.

In the design of the evaluation form, five grades of "excellent", "good", "medium", "poor" and "very poor" in fuzzy mathematics were used to evaluate the feelings of each volunteer in the lifting and placing states. The evaluation results were recorded and organized, as shown in Table 1.

Table 1. Evaluation results of the volunteer.

\begin{tabular}{cccccc}
\hline State & Excellent & Good & Medium & Poor & Very Poor \\
\hline Lifting and transfering & 32 & 18 & 8 & 2 & 0 \\
Placing and transfering & 28 & 24 & 6 & 2 & 0 \\
\hline
\end{tabular}

The votes of five grades for each state are divided by the total number of the volunteer and the evaluation vector $R$ could be obtained, as follows:

$$
R=\left[\begin{array}{ccccc}
0.533 & 0.3 & 0.133 & 0.034 & 0 \\
0.467 & 0.4 & 0.1 & 0.033 & 0
\end{array}\right]
$$

The weight vector $u$ of the comfort of the volunteer could be described as follows:

$$
u=\left[\begin{array}{ll}
u_{1} & u_{2}
\end{array}\right]
$$

where $u_{1}$ is the weight factor in the lifting and transferring state and $u_{1}=0.8, u_{2}$ is the weight factor in the placing and transferring state and $u_{2}=0.2$. 
Combining Equations (17) and (18), the evaluation results $Q$ of patient comfort in these two states can be obtained as follows:

$$
Q=u \times R=\left[\begin{array}{lllll}
0.5198 & 0.32 & 0.1264 & 0.0338 & 0
\end{array}\right]
$$

The maximum membership principle is an appropriate method for the evaluation process, but it is necessary to judge its effectiveness; the specific steps are as follows:

$$
\left\{\begin{array}{c}
Q=\left[\begin{array}{ccccc}
q_{1} & q_{2} & q_{3} & q_{4} & q_{5}
\end{array}\right] \sum_{1}^{n} q_{i}=1 \\
\frac{1}{n} \leq\left(\beta=\max q_{j}\right) \leq 1 \\
1 \leq j \leq n \\
V=\left\{v_{i} \mid v_{i} \rightarrow \max q_{j}\right\}
\end{array}\right.
$$

where $\beta=\max _{1 \leq j \leq n} b_{j}=0.5198 \geq 1 / n=0.5$.

Therefore, the effectiveness of the results is established, and the corresponding conclusion could be obtained that the patient comfort is "Excellent".

\subsection{Test for the Carryring-Capacity of the Patient Transfer Robot}

In order to get the carrying-capacity of the robot, test for the patient transfer part is conducted. Among the five motors in the patient transfer part, the motor of the moving panel bears the maximum force. To obtain this force, we try the following method. Firstly, different weights are loaded on the moving panel. Then, motion process of the patient transfer is performed and the current for the motor is measured and recorded in real-time. Finally, the change curve of the current is obtained, as shown in Figure 20.

The allowable current of the motor- $[I]$ - which is related to the performance of the motor and the reducer, can be obtained by the following equation:

$$
[I] \leq \frac{T_{r}}{T_{n} n_{r t} \eta_{n}} I_{n}
$$

where $T_{r}$ is continuous output torque of the reducer and $T_{r}=25 \mathrm{~N} \cdot \mathrm{m}, T_{n}$ is the rated output torque of the motor and $T_{n}=209.4 \mathrm{mN} \cdot \mathrm{m}, n_{r t}$ is the reduction ratio of the reducer and $n_{r t}=197.75, \eta_{n}$ is the efficiency of the motor and reducer and $\eta_{n} \approx 0.64$ and $I_{n}$ is rated current of the motor and $I_{n}=9.1 \mathrm{~A}$.

Therefore, the following equation could be obtained:

$$
[I] \leq 8.55 \mathrm{~A}
$$

By observing the curve in Figure 20, it can be seen that when the load is $150 \mathrm{~kg}$, the instantaneous peak value of the motor current is $8.51 \mathrm{~A}$, which reaches the allowable current of the robot. Therefore, it can be concluded that the maximum load capacity of the robot is about $150 \mathrm{~kg}$.

According to the previous mechanical structure design and motor parameter selection, the driving force of the moving panel could be obtained:

$$
F_{m}^{\prime}=\frac{2 \cdot T_{n} \cdot \pi}{z_{1} \cdot 9.525} \approx 1267 \mathrm{~N}
$$

where $z_{1}$ is the number of teeth of sprocket 4 and $z_{1}=13$.

The experimental result is consistent with analysis and design of the driving force for the moving panel, so the correctness of the theoretical analysis and calculation was further verified. 


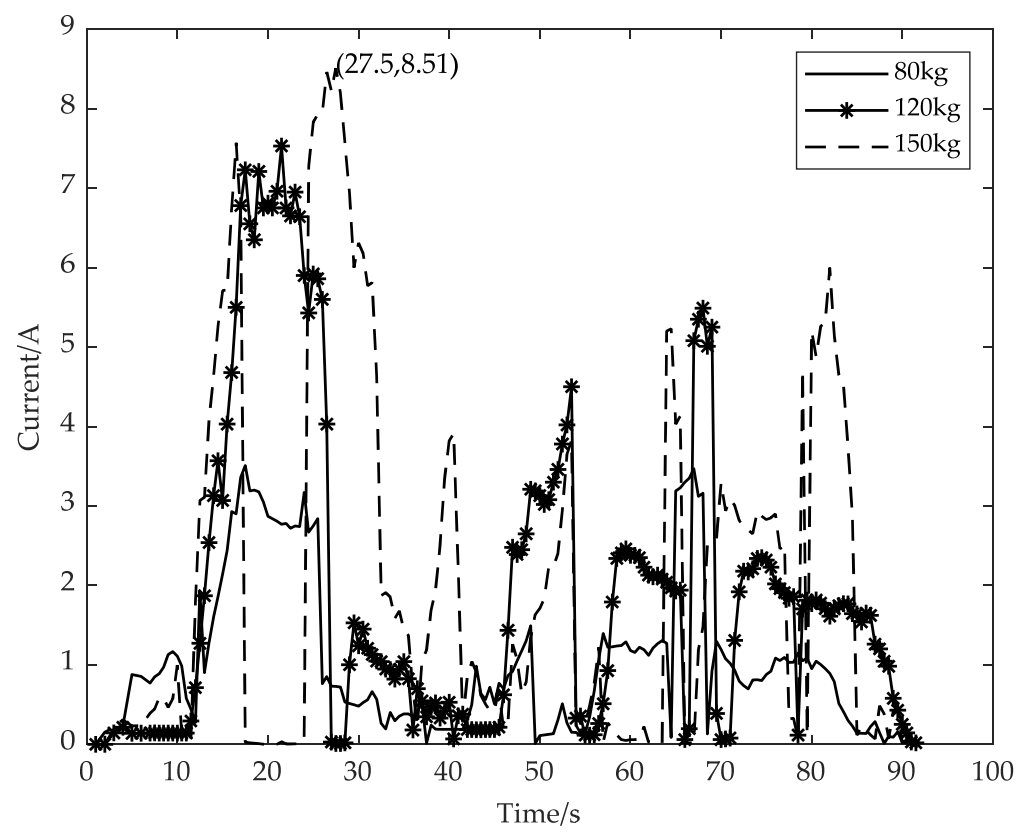

Figure 20. Motor current change curve under different load weight.

\section{Conclusions}

A novel bilateral patient transfer robot is analyzed, computed and designed in detail in this paper; the following conclusions have been obtained:

(1) Based on the clinical patient transfer process, the basic movement mechanism of patient transfer was abstracted, and the working principle of bilateral patient transfer robot was proposed and analyzed.

(2) Force analysis for the patient, the moving panel and the transfer belt were performed, respectively. The corresponding mathematical model between patient comfort and the robot was established, and the key structural parameters of the robot were optimized. The results are that the thickness size (h) of the moving panel is $22 \mathrm{~mm}$, the horizontal projection length size for the inclined surface of the moving panel is $120 \mathrm{~mm}$, and the insertion angle is $8^{\circ}$. Based on the force analysis of the moving panel and the transfer belt, the selection rules of the two driving parts were established, and the minimum force is $990 \mathrm{~N}$ and $1254 \mathrm{~N}$, respectively.

(3) The whole robot is divided into a patient transfer part and a moving part. The key mechanical structures of these two parts were designed, respectively, and the corresponding control system was established. It was confirmed that the functions of the robot can meet the design requirements by experimental research.

(4) The influence of insertion angle on patient comfort was analyzed through 60 volunteers, and the results show that the comfort of patients was excellent. The carrying capacity of the robot was tested by loading different weights on the moving panel, the results show that the robot can carry $150 \mathrm{~kg}$, which is consistent with the theoretical analysis.

In the future, the moving panel of the robot needs to be optimized to make patients feel more comfortable. In addition, the control process of patient transfer is relatively complex, which is not discussed in depth in this paper. In the next work, force position coordination control will be considered, to solve the problem that the transfer belt is too loose when the robot has been used for some time.

Author Contributions: Conceptualization, L.S. and H.W.; methodology, L.S.; software, Y.T.; validation, L.S. and H.W.; formal analysis, L.S.; investigation, L.S.; resources, L.S.; data curation, L.S.; writing - original draft preparation, L.S.; writing—review and editing, Y.T.; visualization, L.S.; supervision, L.S.; project administration, L.S.; funding acquisition, L.S. All authors have read and agreed to the published version of the manuscript. 
Funding: This research was funded by Zhejiang Provincial Natural Science Foundation of China, grant number LGF22E050001 and The Major Scientific and Technological Project in Ningbo City, grant number 2018B10099.

Institutional Review Board Statement: The study was conducted according to the guidelines of the declaration of Helsinki, and approved by the Ethics Committee of College of Mechanical and Electrical Engineering, Ningbo Polytechnic (No. [2021]LLSP(0910)).

Informed Consent Statement: The informed consent has been obtained from the patient(s) to publish this paper.

Data Availability Statement: The original data presented in the study is contained within the article, further inquiries can be directed to the corresponding author.

Conflicts of Interest: The authors declare no conflict of interest.

\section{References}

1. Andersen, L.; Burdorf, A.; Fallentin, N.; Persson, R.; Jakobsen, M.D.; Mortensen, O.S.; Clausen, T.; Holtermann, A. Patient transfers and assistive devices: Prospective cohort study on the risk for occupational back injury among healthcare workers. Scand. J. Work Environ. Heath 2014, 40, 74-81. [CrossRef] [PubMed]

2. Fan, Z.M.; Jamil, M.; Sadiq, M.T.; Huang, X.W. Exploiting multiple optimizers with transfer learning techniques for the identification of COVID-19 patients. J. Healthc. Eng. 2020, 2020, 8889412. [CrossRef] [PubMed]

3. He, M.S.; Yao, Y.F.; Lin, C.; Zhong, M. Research progress and development trends of transfer nursing robot. Mach. Des. Manuf. 2020, 2020, 162-165,169. (In Chinese)

4. Liu, C.H.; Fu, M.; Ding, J.; Yan, Y.J. Best Evidence Summary for In-hospital Transport of Critically III Patients. J. Nurs. 2020, 27, 33-38. (In Chinese)

5. Gudrun, R.; Jill, M.; Lorelli, N.; Hayden, A.K.; Yokom, K.; Lang, E.S.; Lazarenko, G.C.; Joanna, A. Transition in care from EMS providers to emergency department nurses: A systematic review. Prehosp. Emerg. Care 2020, 24, 421-433.

6. Sivakanthan, S.; Blaauw, E.; Greenhalgh, M.; Koontz, A.M.; Vegter, R.; Cooper, R.A. Person transfer assist systems: A literature review. Disabil. Rehabil. Assist. 2019, 6, 1-10. [CrossRef] [PubMed]

7. Wang, Z.F. Medical Electric Transfer Vehicle. C.N. Patent CN111631866A, 9 June 2020. (In Chinese).

8. Mcnulty, C. Body Transfer System and Method. U.S. Patent 7748062, 6 July 2010.

9. Shen, R.C.; Jiang, J.G.; Li, B.H.; Wang, Z.; Wu, Y.P.; Fang, R. Recent advances on patient transferring device. Recent Pat. Eng. 2017, 10, 198-208. [CrossRef]

10. Wang, H.B.; Kasagami, F. A patient transfer apparatus between bed and stretcher. IEEE Trans. Syst. Man Cybern. Part B Cybern. 2008, 38, 60-67. [CrossRef] [PubMed]

11. Wang, H.B.; Fumio, K. Mechatronic design and application of a patient transfer apparatus. J. Mech. Eng. 2009, 45, 68-74. (In Chinese) [CrossRef]

12. Shi, C.; Tang, S.H.; Duan, X.B.; Ning, B.; Chen, X.; Zhang, X. Development of a transfer arm of the robot for transferring the injuried. Bull. Acad. Mil. Med. Sci. 2010, 34, 55-57. (In Chinese)

13. Tian, Y.; Wang, H.B.; Zhang, Y.S.; Su, B.W.; Wang, L.P.; Wang, X.S.; Sang, L.F.; Feng, Y.F.; Niu, J.Y. Design and evaluation of a novel person transfer assist system. IEEE Access 2021, 9, 14306-14318. [CrossRef]

14. Sang, L.F.; Yamamura, M.; Dong, F.; Gan, Z.X.; Fu, J.Z.; Wang, H.B.; Tian, Y. Analysis, design, and experimental research of a novel wheelchair-stretcher assistive robot. Appl. Sci. 2020, 10, 264. [CrossRef]

15. Tian, Y.; Wang, H.B.; Zhang, Y.S.; Su, B.; Du, J.Z.; Wang, X.C.; Feng, Y.F.; Cheng, B.; Niu, J.Y. Structural design and preliminary tests of a novel patient transfer apparatus for medical scenarios. J. Healthc. Eng. 2021, 2021, 2770846. [CrossRef] [PubMed]

16. Mukai, T.; Onishi, M.; Odashima, T.; Hirano, S.; Luo, Z.W. Development of the tactile sensor system of a human-interactive robot "RI-MAN". IEEE Trans. Robot. 2008, 24, 505-512. [CrossRef]

17. Sato, S.; Guo, S.; Inada, S.; Muka, T. Design of transfer motion and verification experiment of care assistant robot RIBA-II. Trans. Jpn. Soc. Mech. Eng. 2012, 78, 1899-1912.

18. Ding, J.; Lim, Y.; Solano, M.; Shadle, K.; ParChris, k.; Lin, C.; John, H. Giving patients a lift-The robotic nursing assistant (RoNA). In Proceedings of the 2014 IEEE International Conference on Technologies for Practical Robot Applications, Woburn, MA, USA, 14-15 April 2014; pp. 1-5.

19. Liu, Y.; Chen, G.; Liu, J.; Guo, S.J. Biomimetic design of a chest carrying nursing-care robot for transfer task. In Proceedings of the 2018 IEEE International Conference on Robotics and Biomimetics, Kuala Lumpur, Malaysia, 12-15 December 2018; pp. 45-50.

20. Liu, Y.X.; Guo, S.J.; Chen, G.L.; Liu, J.Y.; Gan, Z.X. Bionic motion planning and the analysis for human comfort of a piggyback nursing-care robot for transfer tasks. J. Mech. Eng. 2020, 56, 161-170. (In Chinese) 
21. Meng, Q.X.; Lai, X.Z.; Yan, Z.; Wang, Y.W.; Wu, M. Position control with zero residual vibration for two degrees-of-freedom flexible systems based on motion trajectory optimization. Inf. Sci. 2021, 575, 698-713. [CrossRef]

22. Ding, Y.L. Ergonomics, 4th ed.; Beijing Institute of Technology Press: Beijing, China, 2011; pp. 35-155.

23. GB Standards. GB 10000-1988: Chinese Adult Body Size; China Standards Press: Beijing, China, 1988; pp. 50-90.

24. Zhou, M.Y. Ergonomics Application; Shanghai Jiao Tong University: Shanghai, China, 2012; pp. 129-179.

25. Stark, M.; Zapf, A. Sample size calculation and re-estimation based on the prevalence in a single-arm confirmatory diagnostic accuracy study. Stat. Methods Med. Res. 2020, 29, 1-13. [CrossRef] [PubMed] 